RELACult - Revista Latino-Americana de Estudos em Cultura e Sociedade

\title{
A Revitalização do Mercado Público de Pelotas e Sua
}

Ressignificação Social

\author{
La Revitalización del Mercado Público de Pelotas y su Resignificación
}

\author{
Social \\ The revitalization of the Mercado Público de Pelotas and your social \\ redertemination
}

\author{
Bela. Ana Estela Vaz Xavier ${ }^{1}$
}

\begin{abstract}
Resumo
O presente projeto tem como objetivo analisar a política urbana que ensejou a revitalização do Mercado Público Central da cidade de Pelotas/RS, bem como visa identificar as consequências desta intervenção urbana. Esta pesquisa procura investigar os aspectos econômicos, sociais, culturais e sócio-espaciais que estão relacionados com o tema, e, especialmente com o ocupante do local, antes e depois da reforma. Como metodologia, realiza-se um estudo qualitativo e quantitativo, onde serão empregadas técnicas de pesquisa científica. Busca-se ainda, compreender de que maneira a revitalização do Mercado repercutiu no público em geral. Antes da revitalização, o prédio do Mercado necessitava de reformas na parte interna e externa. Hoje, pode-se perceber uma mudança em relação à estruturação interna do prédio, além do fato de que os ocupantes deste espaço público não são os mesmos de antes. Atualmente, o Mercado Público é bastante procurado como um ponto turístico, cultural e de entretenimento, além de oferecer um comércio destinado a pessoas aparentemente de condições mais abastadas. Portanto, há interesse no questionamento acerca das transformações ocorridas neste local que faz parte do cenário do centro histórico da cidade, evidenciando a ressignificação social ocorrida.
\end{abstract}

Palavras-chave: Revitalização; Espaço Público; Espaço Social; Ressignificação Social; Centralidade.

\section{Resumen}

El presente proyecto tiene como objetivo analizar la política urbana que dio origen a la revitalización del Mercado Público Central de la ciudad de Pelotas/RS, además de la identificación de las consecuencias de esta intervención urbana. Esta pesquisa busca investigar los aspectos económicos, sociales, culturales y socio espaciales que están relacionados con la temática, y, especialmente con el ocupante del local, antes y después de la reforma. Como metodología, se realiza un estudio cualitativo y cuantitativo, donde serán empleadas técnicas de pesquisa científica. Se busca además, comprender de qué manera la revitalización del Mercado repercutió en el público en general. Antes de la revitalización, el predio del Mercado necesitaba de reformas en la parte interna y externa. Hoy, se puede percibir una mudanza en relación a la estructuración interna del predio, además del facto de que los ocupantes de este espacio público no son los mismos de antes. Actualmente, el Mercado Público es bastante procurado como un punto turístico, cultural y de entretenimiento, además de ofrecer un comercio destinado a las personas aparentemente de mejor condiciones financieras. Por lo tanto, ha interese en el cuestionamiento a cerca de las transformaciones ocurridas en este local que hace parte del escenario del centro histórico de la ciudad, evidenciado la resignificación social ocurrida.

Palabras-clave: Revitalización. Espacio Público. Espacio Social. Resignificación Social. Centralidad.

\footnotetext{
1 Bacharela em Comunicação Social; mestranda em Sociologia; Universidade Federal de Pelotas - UFPEL; Pelotas, Rio Grande do Sul, Brasil; aestelars@gmail.com.
} 


\begin{abstract}
This project aims to analyze the urban policy that gave rise to the revitalization of the Central Public Market in the city of Pelotas/RS, identifying the consequences of this urban intervention as well. We seek to investigate the economic, social, cultural and socio-spatial aspects related to the matter and, particularly, to the local business people who explored the place before and after those renovations. A qualitative and quantitative study methodology was adopted and scientific research techniques were employed. Additionally, it is intended to understand how the market revitalization affected the general public. Before the renovations, the building needed improvement both inside and outside. It is currently possible to notice that not only the internal structure of the building has been changed, but also that the people frequenting this public space are no longer the same. Nowadays, the Public Market is very popular as a tourist, cultural and entertainment destination, besides offering business services that apparently fit financially better-off people. Therefore, there is interest in questioning the changes underwent by this place, which is part of the scenery of the historical center of the city, so as to show the social redefinition occurred.
\end{abstract}

Keywords: Revitalization; Public space; Social space; Social redefinition; Centralization.

\title{
1 Introdução
}

A presente pesquisa busca investigar as consequências da revitalização do Mercado Público Central da cidade de Pelotas que levou a uma mudança no que tange ao uso do espaço público pelos ocupantes, sejam eles, frequentadores ou permissionários, resultando na ressignificação do local. Com a restauração do prédio do Mercado e com a criação do Largo, ocorreu uma ressignificação para os comerciantes de bens e serviços, expositores e frequentadores atuais deste espaço social.

A Revitalização do meio ambiente urbano degradado, pode tanto acarretar benefícios quanto prejuízos na vida da população, pois resulta na ressignificação social do ambiente.

A resolução do Conselho Nacional do Meio Ambiente, conceitua meio ambiente como sendo "o conjunto de condições, leis, influência e interações de ordem física, química, biológica, social, cultural e urbanística, que permite, abriga e rege a vida em todas as suas formas". (CONAMA 306:2002)

O meio ambiente urbano, mediador do sujeito com a sociedade, busca atingir o equilíbrio do desenvolvimento entre cultura, urbanização e conservação ambiental no espaço social, com relevância para interação social, evolução e reforço da identidade local.

Compreender o processo de revitalização do Mercado Público Central - MPC , construído em 1848, localizado no centro histórico da cidade de Pelotas, nos levou a pesquisar os fenômenos sociais, culturais e econômicos nele emergentes, que implicou na ressignificação social deste espaço público.

O Mercado Público é um prédio histórico tradicional da cidade de Pelotas/RS, que foi tombado no ano de 1985, ele fez parte do rol dos prédios que foram restaurados, a partir da requalificação da área central de Pelotas, que contou com recursos do Programa Monumenta, 
do Ministério da Cultura e do Instituto do Patrimônio Histórico Nacional - IPHAN (BRASIL, 2012).

A articulação das intervenções urbanas com vistas a revitalização das áreas centrais das cidades tendem a atrair capital e pessoas de classe médias e altas, tornando-as convidativas do ponto de vista turístico e comercial, por meio da ressignificação social dos espaços urbanos (HARVEY apud FRÚGOLI JR., 2000).

Deve-se ressaltar que a intervenção urbana decorre, na maioria das vezes, de decisões políticas, do poder público e setores do capital, favorecendo a especulação imobiliária e do capital financeiro e comercial. De acordo com Peixoto (2009), a recuperação física e ambiental ocorre especialmente nos centros históricos das cidades, pelo fato de que este tecido urbano é formado por habitações antigas, além de que a recuperação contribui para o equilíbrio social, com atividades culturais e turísticas, e portanto, a valorização e conservação de patrimônio localizado no centro é uma tarefa coletiva.

A presente pesquisa observou quais os fenômenos envolvidos no processo de revitalização do Mercado Público Central de Pelotas e seus arredores. A Revitalização do espaço público degradado, pode tanto acarretar benefícios quanto prejuízos na vida da população, dado que muitas vezes pode modificar as atividades econômicas originárias no meio ambiente construído. Por isso o foco da pesquisa é investigar a ressignificação social do uso do Mercado Público, após sua revitalização.

O Mercado Público, entende-se como o espaço público, constituinte do meio ambiente urbano, onde os indivíduos se encontram no dia a dia movidos por alguns interesses comuns e outros diferentes. Consequentemente, esse espaço público possui uma centralidade que atrai pessoas, objetos, signos, estabelecendo entre esses elementos relações de troca seja econômica seja simbólica as quais sustentam processos de interação social.

Tendo por objetivo geral investigar o impacto da revitalização do uso do Mercado Público para os antigos e novos ocupantes, a pesquisa observou a ressignificação das práticas construídas pelos comerciantes antigos e atuais, pelos expositores e frequentadores do Mercado. Propõe-se, identificar os agentes promotores e responsáveis pela produção e execução do projeto de revitalização, analisando a proposta inicial, juntamente com seus objetivos e sua repercussão, além de averiguar até que ponto os antigos permissionários tinham conhecimento do projeto de revitalização e em que condições eles participaram ou atuaram na tomada de decisões relativamente à reforma.

É notório o fato de que houve um processo de higienização nos arredores do Mercado Público, excluindo do local as chamadas classes perigosas (frequentadores de bares, de baixa 
renda, que consumiam bebidas como a "cachaça", as prostitutas, os moradores de rua, mendigos e outros). Essa higienização é correlata ao enobrecimento da área central da cidade, o que demonstra indícios de "gentrificação" (enobrecimento) no local.

Outro objetivo específico é estudar o perfil sociodemográfico do frequentador do Mercado Público, para discutir e refletir se houve ou não mudança, em decorrência da revitalização. E, por fim, pretende-se analisar os documentos pertinentes à revitalização/requalificação do Mercado.

Ao estudar as mudanças estruturais do local, será possível compreender no que resultou, após a reforma, procurando saber se houve uma descaracterização do Mercado, que se comparado a outros mercados públicos, perdeu sua singularidade de um local para vendas de produtos populares e tradicionais. Pois, podemos presenciar e vivenciar práticas comerciais típicas em outros Mercados Públicos, que mesmo após passarem por reformas e outras intervenções mantiveram as características essenciais da forma de comércio.

Neste sentido, menciona Arantes (2009), que na re-qualificação de centros históricos tem prevalecido critérios de intervenção que reforçam a dimensão estética monumental e os sentidos alegóricos dos bens patrimoniais, em desvantagem do uso que faziam os antigos ocupantes, o que parece ter ocorrido no Mercado Público de Pelotas.

Conforme o Relatório do Programa Monumenta (PELOTAS, 2002), a requalificação da área central de Pelotas, se deu por meio das intervenções de restauro e reforma dos prédios pertencentes ao centro histórico da cidade, abrangendo o Mercado Central e a criação do Largo Edmar Fetter, que são objetos deste estudo e que despertaram maior interesse por ter manifestamente se salientado no que se refere a sua ressignificação social.

Antes da reforma, o Mercado Público possuía corredores com aparência menos alargada, com bancas/lojas maiores, com áreas de tamanhos diversos, além do que não haviam regras estabelecidas para a disposição dos produtos nas prateleiras e no exterior das lojas, tanto é que tratava-se de prática comum os comerciantes exporem suas mercadorias pelos corredores na frente e nas laterais das lojas, porém, o Mercado estava abandonado quanto a limpeza, iluminação e "organização" (se é que devemos pensar em Mercados organizados, sem o toque local e cultural dos ocupantes).

Após a revitalização, no Mercado, podemos identificar as alterações físicas relativas ao seu interior, que recebeu uma aparência mais arejada e renovada, houve um alargamento nos corredores e diminuição da área útil das bancas que foram adequadas pelo projeto de reforma ao novo modelo proposto, porém, as regras impostas aos permissionários são mais 
limitadoras e rígidas e também pode-se perceber que os ocupantes do local não são mais os mesmos na sua totalidade.

Além das mudanças físicas e arquitetônicas, que presenciamos principalmente na parte interna do Mercado Público, podemos perceber que outros fenômenos ocorreram no local, portanto, com a presente pesquisa buscamos identificar e compreender quais foram.

Hoje, encontram-se na parte interna do Mercado apenas quatro dos antigos ocupantes, e, na parte externa do prédio, foi possível identificar outros poucos antigos comerciantes, dos quais dois estão nas barbearias, localizadas ao sul do Mercado, dois nos bares mais populares, a casa de peixes e aquários e em duas peixarias que permaneceram em funcionamento durante o período de reforma do prédio, portanto, no Mercado somente 11 bancas são ocupadas por permissionários que conseguiram retornar ao local com seus comércios e serviços.

Os demais ocupantes do Mercado Público são novos, ou seja, instalaram suas atividades comerciais e de prestação de serviços depois da revitalização ocorrida. No entanto, o que percebe-se é que, passados quase quatro anos da entrega das obras, o Mercado possui um grande número de lojas desocupadas, que encontram-se fechadas, presume-se que isso ocorra em virtude do alto preço do aluguel cobrado aos permissionários e em decorrência da redução da área útil das lojas/bancas. Sabe-se que aumentaram o número de bancas após a reforma do Mercado, antes contava-se com 85 entre lojas, quartos e peixarias e atualmente totalizam 95 espaços destinados ao comércio, à gastronomia, ao espaço cultural e informação turística e peixarias. Portanto, será de suma importância, a abordagem acerca dos ocupantes das bancas e lojas do Mercado antes e depois da sua revitalização.

O Mercado não voltou a ser como era antes, ele tornou-se um espaço de sociabilidade destinado sobretudo a atividades culturais, de entretenimento e de lazer, além do comércio. No seu exterior, diferentemente do que ocorria antes da revitalização, o Mercado passou a ser frequentado também à noite, especialmente nos bares e restaurantes, instalados principalmente na frente norte do Mercado, voltados para o Largo.

A partir de então, busca-se investigar se as mudanças ocorridas no Mercado e no seu entorno acarretaram alguma espécie de exclusão social ou segregação a partir da higienização que acompanhou a Revitalização. Pretende-se averiguar se ocorreram outros processos sociais como a "gentrificação" do local, que levou a migração dos antigos ocupantes do Mercado a outros locais, bem como a perda da identidade e do sentimento de pertencimento por parte dos ocupantes que ali permaneceram ou ainda dos que dali saíram, além de outros fatores sócio econômicos que provavelmente fazem parte deste contexto. 
O problema desta pesquisa está em averiguar se há idiossincrasia entre os antigos e novos permissionários do MPC em relação à ressignificação social do espaço, após a revitalização, além de buscar compreender se os fenômenos envolvidos na revitalização do MPC acarretaram a exclusão ou segregação espacial de um público frequentador com menor poder aquisitivo e menor capital social. Outro problema de pesquisa que se evidenciou foi buscar saber se após a revitalização houve a requalificação da centralidade de atividades comerciais e culturais no espaço público e por fim, pretende-se pesquisar se ocorreu de fato a ressignificação do espaço público de Mercado para os sujeitos sociais.

No Mercado Público Central, como mencionado anteriormente, o comércio tinha uma aparência informal, despojada, os comerciantes podiam expor seus produtos sem regras, de modo desordenado e até mesmo nos corredores, os produtos comercializados eram de outras espécies, havia a casa de carnes, de sementes, as fruteiras, os calçados que eram destinados a todos os públicos, especialmente aos consumidores "de menor poder aquisitivo".

Santos (apud BALSAN; UEDA, 1998, pp. 78-9) diz: “é, de fato, o mercado que autoriza a presença simultânea na cidade (...) de tantas formas de realização econômica diferentes e até contrastantes". É nessa direção, que surgem os questionamentos acerca da ressignificação do Mercado Público de Pelotas após sua revitalização.

No que tange as ruas que contornam o prédio do Mercado também pode-se perceber mudanças, já que sua revitalização incluiu a higienização do local. No entanto, esta pesquisa é ensejada pelo fato de que se acredita que o Mercado Público não manteve seu uso de origem, destinado a concentração de comércio popular, como tradicionalmente ocorre. Tudo isso leva a crer que restou lesionada sobretudo a memória e a identidade de seus antigos comerciantes, ocupantes e frequentadores do Mercado.

Com a revitalização do Mercado Público Central que reabriu suas portas em 2012, os fenômenos sociais que estão envolvidos passaram a chamar a atenção de muitos e, paradoxalmente, pode-se considerar que alguns destes fenômenos passam despercebidos, embora se façam presentes.

\section{Referencial Teórico}

O referencial teórico a ser utilizado como suporte a este estudo sociológico será devidamente referenciado neste tópico a fim de facilitar a compreensão do se pretende estudar. Neste sentido, os conceitos basilares, também serão evidenciados um a um para que o leitor possa orientar sua leitura para o entendimento do tema proposto. 
De acordo com Lefèbvre (2008, p. 90), “o urbano se define como lugar onde as diferenças são conhecidas, reconhecidas e postas à prova". Neste sentido, o urbano é uma totalidade heterogênea e centralizada, marcada pelas particularidades, pelas diferenças que são o móvel da sociedade, pois a cidade acolhe o que é diferente, assim, pode-se afirmar que o urbano trata de centralizar tudo. As diferentes práticas agrupadas se confrontam, mas também se integram através das ações dos indivíduos. No urbano ocorre a reunião das diferenças das relações sociais, nele estão as simultaneidades e consequentemente, os conflitos. A cidade centraliza as criações, que carecem de trocas, aproximação e relações. Segundo Lefèbvre (2008, p. 111), "a cidade cria a situação urbana, onde as coisas diferentes advêm umas das outras e não existem separadamente, mas segundo as diferenças”.

Para esta pesquisa importa conceituar o urbano, pois o objeto de estudo está inserido no meio urbano da cidade de Pelotas e como bem menciona Lefèbvre (2008), o urbano é cumulativo de todos os conteúdos, ele possui signos que permitem a reunião das coisas, que propiciam espaços de intensa interação social.

Sendo assim, entende-se que após a revitalização do Mercado Público, ocorreu a ressignificação deste espaço social, bem como pode ter ocorrido o retorno da centralidade de atividades culturais e de entretenimento, pois, o urbano visto como forma, possui tendência à centralidade, pelos distintos modos de produção e de relações de produção. Além do mais, o Mercado Público de Pelotas, ao contrário de outros Mercados, que normalmente se encontram localizados em zonas portuárias, faz parte do centro histórico da cidade, está localizado bem na área central, administrativa e cultural. Após a revitalização o que percebe-se é que o Mercado e o Largo vêm sendo mais frequentados como forma de lazer e entretenimento, o espaço é cada vez mais utilizado como meio de sociabilidade entre os frequentadores que procuram atividades culturais, o que antes da reforma não acontecia há muitos anos, pois estava abandonado e perigoso.

Em relação à centralidade e seu resgate, processo pelo qual muitas cidades vêm passando, é tema que Frúgoli Jr. (2006) busca estudar e compreender, em especial na grande São Paulo, analisando espaços decorrentes da expansão urbana, com os projetos que visavam a revitalização de áreas que estavam deterioradas do ponto de vista urbano-ambiental, pois eram espaços que contavam com a presença de mendigos, ambulantes, assaltantes dentre outros grupos de pessoas consideradas perigosas e indesejáveis para a população de classe mais abastada. Frúgoli Jr. (2006), se opõe ao que chamamos de higienização do espaço público que passa pela revitalização/requalificação, onde ocorre a expulsão de camelôs, pois o comércio informal não é aceito, além de outras expulsões de pessoas consideradas de risco 
para segurança pública. Sendo assim, Heitor Frúgoli Jr. se coloca contra a segregação social ou apartação sócio-espacial, posição que encontramos especialmente em sua obra Centralidade em São Paulo (FRÚGOLI JR., 2006).

Da mesma maneira que o autor consegue identificar casos de apartação sócio-espacial e a higienização do espaço público nas áreas que foram revitalizadas na cidade de São Paulo SP, busca-se nesta pesquisa observar se ocorreram ou não casos semelhantes na cidade de Pelotas - RS, com a requalificação do Mercado Público Central e de seu entorno.

Em concordância com o pensamento de Park (1973), a cidade é muito mais do que é representado por seus componentes e instituições e setores administrativos. Para este autor, "a cidade é um estado de espírito, um corpo de costumes e tradições e dos sentimentos e atitudes organizados, inerentes a esses costumes e transmitidos por esta tradição... é um produto da natureza humana" (PARK, 1973, p. 26).

Baseado no conceito de cidade acima descrito por Park, é que vê-se a necessidade de sua utilização nesta pesquisa sociológica, posto que, pretende-se estudar a ressignificação social do espaço social, no que toca os costumes, as tradições, os sentimentos, as práticas sociais, que voltaram a acontecer no centro da cidade após a revitalização do Mercado Público. Do ponto de vista do autor Park (1973), com o qual ora compactua-se, a cidade possui uma vida propriamente sua, fazendo com que exista um limite para as modificações arbitrárias possíveis de se fazer em relação a sua estrutura e em relação a sua ordem moral.

Para Louis Wirth, as cidades exercem influências sobre a vida social do homem, pois elas são a moradia e local de trabalho do homem moderno, assim como é o centro iniciador e controlador da vida econômica, política e cultural que atraiu as localidades mais remotas do mundo para dentro de sua órbita interligando diversas áreas, diversos povos e diversas atividades num único universo. De acordo com este autor, a definição de cidade para fins sociológicos é: “cidade é um núcleo relativamente grande denso e permanente, de indivíduos socialmente heterogêneos" (WIRTH, 1973, p. 96). Para ele o problema central do sociólogo da cidade é descobrir as formas de ação e organização social que emergem em grupamentos compactos, relativamente permanentes, de grande número de indivíduos heterogêneos. $\mathrm{O}$ direito à cidade passa pelo sentimento de pertencimento do cidadão, pelo acolhimento e pela convivência entre os diferentes, onde há a percepção de que a sociedade serve a todos os cidadãos, sem distinção, não permitindo qualquer tipo de exclusão social.

A cidade deve estar voltada para o compartilhamento do espaço público, considerando a igualdade para a aproximação e convívio entre as pessoas, com um maior grau de alteridade, onde o respeito à diversidade atua na saúde física e psíquica do homem da cidade, na sua 
coexistência no espaço público. No entanto, o que entende-se ter ocorrido no Mercado Central, foi justamente o contrário, pois suspeita-se de prática segregatória em relação a certos grupos de pessoas.

O espaço urbano, ocupado pelo homem citadino, que vai ao longo da vida estabelecendo relações de proximidade e de distanciamento de outros citadinos, em vários contextos, integra o que busca-se compreender neste trabalho, que tem por objetivo verificar o que ocorreu no espaço do Mercado Público de Pelotas no tocante aos seus atores e grupos sociais, bem como o modo de interação e sociabilidade, que levou a ressignificação social e resgate da centralidade da cidade após a sua revitalização.

De acordo com Serpa (2011, p. 9), “o espaço público é aqui compreendido, sobretudo, como o espaço da ação política ou, ao menos, da possibilidade da ação política na contemporaneidade”. Serpa, a partir de uma perspectiva crítica, afirma que mesmo sendo considerado público poucos se beneficiam desse espaço teoricamente comum a todos. $\mathrm{O}$ espaço público pode ser visto como espaço simbólico, que relaciona sujeitos diversos e percepções na produção e reprodução desses espaços através da intersubjetividade.

Cabe aqui analisar o que tem sido considerado espaço público na atualidade, pois interessa a esta pesquisa compreender as muitas formas de interação social, modos de consumo, capital social e cultural, dentre outros elementos que se apresentam como determinantes das identidades sociais no espaço público das cidades, neste caso, o espaço público do Mercado Central, com vistas a sua ressignificação.

Nas cidades brasileiras podemos verificar uma fragmentação do tecido sociopolítico espacial e a formação de encraves territoriais no tecido urbano, sofisticando as formas de auto-segregação dos habitantes (SERPA, 2011). A esfera pública além de nos reunir na companhia um dos outros também evita que colidamos uns com os outros, no entanto, a dificuldade que a sociedade encontra no convívio em massa é a de juntar os indivíduos, relacionando-os e separando-os dialeticamente.

Os habitantes dos espaços urbanos possuem sistemas de significações a partir do percebido e do vivido, pelo fato do seu habitar desejado, destacados na teoria de Henri Lefèbvre. Entretanto, identificamos um grande vilão, que é o Estado, como participante das parcerias entre o público e o privado, que põe em ação estratégias urbanas, que parecerem produzir objetos e imagens, que na verdade nada mais são do que testemunhos da desintegração da cidade contemporânea.

De acordo com Bourdieu (1996), autor eleito para conceituar espaço social nesta pesquisa sociológica, a ideia de diferenciação, de separação, faz parte do funcionamento da 
noção de espaço, conjunto de posições distintas e coexistentes exteriores e definidas umas em relação às outras pela exterioridade mútua e por relações de proximidade ou de distanciamento assim como por relações de ordem (acima, abaixo e entre). Portanto, para Bourdieu (1996), quanto maior a proximidade de suas dimensões, os agentes sociais, possuem mais pontos incomuns, pois as distâncias espaciais, para ele, equivalem as distâncias sociais. Interessa para esta pesquisa compreender esta conceituação, pois os agentes no espaço social estão distribuídos na primeira dimensão de acordo com o volume global de capital (econômico e cultural), na segunda dimensão de acordo com o a estrutura desse capital (peso relativo do volume do capital econômico e cultural) e ainda na terceira dimensão conforme a evolução do volume e da estrutura de seu capital no decorrer do tempo.

Para Bourdieu (1983), o mundo social é representação e vontade, existir socialmente é também ser percebido como distinto. No espaço urbano há um sistema de relações onde a alteridade está evidenciada delimitando-o de forma que as lutas de identidades moldam as divisões do mundo social, criando ou desfazendo os grupos. O espaço social de acordo com Bourdieu (1996), pode ser comparado ao espaço geográfico que conforme a proximidade dos grupos ou das instituições produzem as interações que proporcionam experiências mais imediatas, que podem ser tocadas.

No entanto, o autor diz que a interação nunca está inteira na interação que se apresenta na observação, segundo ele,

o espaço social está construído de tal modo que os agentes que ocupam posições semelhantes ou vizinhas estão colocados em condições semelhantes e submetidos a condicionamentos semelhantes, e têm toda a possibilidade de possuírem disposições e interesses semelhantes, logo, de produzirem práticas também semelhantes (BOURDIEU, 1996, p. 155).

E, é neste momento, que se pretende compreender as prováveis questões sobre os interesses comuns e conflituosos, que acredita-se que estão presentes no Mercado Público como espaço social, pois baseando-se na teoria de Pierre Bourdieu, a proximidade no espaço social significa o intercâmbio de práticas e preferências igualitárias e por outro lado o afastamento implica em práticas e preferências distintas.

Bourdieu (1996) apresenta o espaço social como sendo o local onde se organizam e se relacionam as diferenciações dispostas topologicamente de acordo com as posições sociais, porém, este conceito só pode ser tomado ser for levado em consideração o universo relacional, ou seja, as disposições ou habitus, que são atribuídos a este ou àquele grupo determinado em um dado recorte espacial e temporal bem como em uma dada situação de 
oferta de bens. Bourdieu (1996, p. 27) diz que "o espaço social é a realidade primeira e última já que comanda até as representações que os agentes sociais podem ter”.

Os usuários do espaço, segundo Serpa (2011), contribuem para a amplificação da esfera privada no espaço público, fazendo emergir uma sorte de estranhamento mútuo de territórios privados, expostos, no entanto, a uma visibilidade completa. No mundo contemporâneo, o Estado funciona como uma administração caseira, formando um lar coletivo, que ganha significado e sentido através das coletividades políticas, sendo assim, o domínio público se afasta de uma conotação política e vai assumindo um significado cada vez mais "social", interditando a possibilidade da ação, como defendido por Serpa.

Como bem menciona Serpa (2011, p. 39):

Em um mundo onde a cultura transformou-se em lazer e diversão, existe uma distância mais social que física, separando os novos equipamentos públicos daqueles com baixo capital escolar, o que mostra que segregação espacial e segregação social nem sempre servem para designar a mesma coisa.

Neste sentido, conforme o pensamento de Serpa, pretende-se analisar supostos casos de segregação social e/ou espacial que possam ter ocorrido no espaço social do Mercado Público de Pelotas após sua revitalização.

A sociabilidade é um conceito básico que deve ser analisado, pois nele está a possibilidade de investigar a sociedade face às interações recíprocas dos seus indivíduos, segundo Simmel (2006). A alteridade encontrada nos espaços públicos está interligada às questões de formação de identidades sociais, cuja construção ocorrerá a partir da interação, das transações, das relações ou contatos entre grupos distintos.

Para Simmel (apud FRÚGOLI JR., 2007, p. 9), a sociedade nasce nos processos de interação microssociológicos, sendo necessário que "os indivíduos em interação 'uns com, para e contra os outros' formem, de alguma maneira, uma 'unidade', uma 'sociedade' e estejam conscientes disso". Neste sentido, para Simmel o conceito de sociabilidade permitirá melhor compreender o modo como se organiza a sociedade através de uma associação básica, por tratar-se de tipo ideal entendido como "social puro", desprovido de interesses, de propósitos ou objetivos, que não seja a própria interação, vivida como espécie de jogo com suas regras implícitas, sendo uma delas a de que todos fossem iguais.

Georg Simmel, como menciona Frúgoli Jr., diz que a sociedade é flexível e não rígida, sendo o conflito uma forma de socialização. Para ele, não há uma sociedade "como 
tal", mas um movimento constante que separa ou aproxima constelações constituídas (SIMMEL apud FRÚGOLI JR., 2007).

Segundo Remy (2012), de acordo com o pensamento de Simmel, a sociedade é composta de grupos desarmoniosos, que estão em constante conflito, que tem por objetivo as funções muito mais que as disfunções, possibilitando a adaptação do indivíduo e o ajuste das relações sociais, através do consenso. E, partindo deste pressuposto, busca-se verificar se há conflito entre antigos e novos ocupantes do espaço do Mercado Público Central.

Neste ponto, faz-se uma breve passagem conceitual pelo termo gentrificação, a fim de entender se este processo ocorreu ou se pode ter ocorrido no Mercado Público após sua revitalização.

O termo gentrification surgiu com os estudos da socióloga britânica Ruth Glass pela primeira vez, mas posteriormente foi sendo cada vez mais utilizado em muitos estudos com acepções diversas. De acordo com Rubino (2009), Glass, ao falar em gentrificação, se referia às casinhas modestas e geminadas das classes trabalhadoras de Londres, que foram invadidas pela classe média. Posteriormente, o termo gentrificação, segundo Rubino (2009) foi tomando outras nuances, com vertentes de pensamentos distintos em relação ao processo, pois de um lado haviam autores que salientavam a ênfase de imóveis em áreas abandonadas vinculados ao papel das finanças públicas e privadas, e por outro lado, na ênfase das novas classes médias urbana, com toda a sua prática de consumo e suas demandas.

Neil Smith entende a gentrificação como sendo o "retorno do capital e dos segmentos sociais de maior poder aquisitivo ao centro" (SMITH apud PEREIRA, 2014, p. 310). Para ele este processo resulta numa paulatina substituição de seus antigos moradores e frequentadores, que dificilmente conseguem resistir a pressão decorrente das mudanças provocadas pelo enobrecimento. Para Smith, o processo de gentrificação está muito mais vinculado às forças econômicas do que às culturais.

De acordo com Harvey (1992), pode ocorrer o fenômeno da gentrification, ou "enobrecimento", quando as áreas centrais da cidade são revitalizadas e passam a ser habitadas por grupos sociais de maior poder aquisitivo, com tendência à criação de novos enclaves residenciais e à expulsão dos moradores originais, de baixa renda ou de origem étnica distinta daquela dos novos moradores.

No entanto, Gutiérrez (2014) afirma que a gentrificação trata-se de um processo que não é homogêneo entre as cidades nem dentro delas próprias, onde convergem interesses tanto público como privados, que surgem ao redor deste e que em geral resulta excludente, diferenciador e enfocado no consumo. Ao compreender o que propõe Gutiérrez relativamente 
ao termo "gentrificación", encontra-se base para levantar a hipótese de ter ocorrido tal processo no espaço do Mercado Público Central de Pelotas, pois suspeita-se que há existência de práticas excludentes e pode-se perceber mudanças nas práticas de consumo do local.

Segundo Zukin (2014, p. 10):

A gentrificação é uma ótima estratégia para preservar o tecido físico da cidade: casas bonitas, ruas bonitas, usos variados, cafés, pequenas lojas. Mas os gentrificadores têm altos rendimentos se comparados com a maioria dos habitantes da cidade, então, eles alteram a economia local. Eles apoiam mercados de consumo cultural - cafés chiques em vez do café comum do dia a dia, restaurantes gourmet mas não apoiam as pequenas lojas e as feiras livres das quais os residentes de menor renda dependem.

Pretende-se fazer um breve apanhado conceitual dos termos revitalização e requalificação, já que este último é o termo utilizado no Projeto Monumenta e pelo IPHAN constante nas propostas destinadas à reforma e à restauração dos prédios históricos da cidade de Pelotas.

Para Peixoto (2009), a requalificação urbana corresponde a uma prática de planificação ou de proteção urbanística de equipamentos e de infra-estruturas expostos à degradação e à obsolescência funcional. Peixoto (2009) menciona que na Carta de Lisboa, requalificação refere-se a operações dirigidas a espaços não residenciais, sendo que as mesmas apostam em fomentar nesses espaços novas atividades mais adaptadas aos contextos urbanos contemporâneos. De acordo com Peixoto (2009, p. 46):

a requalificação urbana dirige-se mais ao seu entorno e ao espaço público, ou, nas operações urbanas de larga escala, à reconvenção funcional de um dado espaço. $\mathrm{O}$ objetivo último da requalificação passa por (re) introduzir "qualidades urbanas de acessibilidade ou centralidade a uma determinada área".

Neste sentido, Peixoto (2009) diz que o termo revitalização aparece associado à ideia de requalificação urbana, podendo ser considerado sinônimo para uma realidade que busca conjugar a reabilitação física, arquitetônica e urbana dos centros históricos visando revalorizar as atividades econômicas e culturais que ai se desenvolvem. Desta forma, verificar-se a proximidade dos termos revitalização (que ora adota-se) e requalificação (termo adotado pelo Iphan e Projeto Monumenta), ambos utilizados neste trabalho de pesquisa sociológica que pretende compreender a ressignificação social do Mercado Público após a sua revitalização.

Deve-se atentar para a diferença conceitual das terminologias utilizadas nas intervenções urbanas. De acordo com a Carta de Lisboa (de 1995), o conceito de reabilitação se apresenta como sendo uma estratégia de gestão urbana, que induz a compreensão de seu 
significado como sinônimo de requalificação e que em seguida aproxima esse conceito da definição de revitalização (VARGAS; CASTILHO, 2006). Ambos os conceitos carregam a necessidade de dar nova vida às áreas decadentes da cidade.

No entanto, há que se considerar que, de acordo com as autoras, Vargas e Castilho (2006), existe uma diferença entre a reabilitação, que exige que sejam mantidas a identidade e as características do lugar e a requalificação que pode ser adotada em zona com ou sem identidade. $\mathrm{Na}$ interpretação das mesmas, o termo revitalização se aproxima muito do termo de requalificação e ambos os termos implicam em dar nova vida, nova atividade econômica às áreas decadentes das cidades.

Nas operações dirigidas às áreas urbanas antigas, "a revitalização de um centro histórico exige a manutenção da população (...), a atração da população que o abandonou, assim como de novos usuários" (CASARES apud PEIXOTO, 2009, p. 46). E, Peixoto (2009) menciona Peña, quando ele diz que o objetivo da revitalização é conservar e reabilitar o patrimônio do centro histórico, devolvendo a sua importância funcional mediante a revitalização das atividades comerciais e dos serviços tradicionais, além de outros, que tornem o local atraente para aqueles visitantes interessados pela história e pela cultura locais. Neste sentido, observa-se que o que está ocorrendo no espaço público do Mercado Central, por hora, se distancia do que se espera da revitalização.

Porém, há que levar em consideração o fato de que a "reposição da totalidade" implicaria num falso histórico, “afinal toda a cidade é histórica, pois ela é a materialização do processo histórico; é impossível não deixar de atribuir juízo de valor ao escolher as áreas para intervenções" (VARGAS; CASTILHOS, 2006, p. 62). Sendo assim, como mencionam Vargas e Castilho (2006), no caso da renovação urbana que abre espaço para a reabilitação (revitalização, regeneração), as práticas urbanísticas reconhecem o valor da história na cidade e do homem enquanto ser cultural.

Ao enfatizar as questões nas quais se apoiam os projetos de revitalização, com suas motivações e necessidades, assim como suas consequências para a população, sejam elas negativas ou positivas, dispõe-se de uma série de argumentos para embasar este trabalho de pesquisa no que concerne aos assuntos de interesse público e privado. Neste sentido, Harvey (1992) considera a promoção da revitalização de áreas centrais das metrópoles, como sendo um modo de atrair capital e pessoas, ressiginficando os espaços urbanos, tornando-os mais convidativos do ponto de vista comercial e turístico. 
Na proposta de reciclagem do Mercado Público de Pelotas, Villela (1995), menciona alguns conceitos de revitalização editados pela revista Projeto $\mathrm{n}^{\circ} 160$ e utiliza o seguinte conceito:

revitalização é incentivar a atribuição de novos usos e funções, tornando as edificações compatíveis com as necessidades de uma sociedade contemporânea e apresentando-as como alternativa para a crescente demanda de novas construções e equipamentos urbanos (VILLELA, 1995, p. 8).

A princípio, acredita-se ser este o conceito que mais se aproxima do processo de requalificação/revitalização do Mercado Público de Pelotas, utilizado na prática pelos agentes operadores e promotores da reforma.

\section{Formulação de Hipóteses}

As hipóteses levantadas na presente pesquisa são: 1. A revitalização do Mercado Público Central de Pelotas contribuiu para o requalificação da centralidade de atividades comerciais e culturais no espaço público; 2. A revitalização repercutiu na atração de um público com poder aquisitivo e escolaridade maiores e a evasão de um público com menor poder aquisitivo consequentemente com menor capital social; 3. A revitalização do Mercado Público resultou na ressignificação do uso deste espaço público pelos atores sociais, ou seja, pelos antigos e atuais permissionários, pelos expositores culturais e artistas e ainda, pelos frequentadores; 4. Há idiossincrasia entre os permissionários atualmente estabelecidos no Mercado Público Central e os antigos permissionários que dali migraram para outros prédios/locais comerciais, no tocante à ressignificação do Mercado em decorrência da revitalização.

Este trabalho procura, então, observar e identificar as mudanças ocorridas no Mercado Central de Pelotas após sua revitalização, visando a compreensão dos fenômenos sociais que ocorreram e estão ocorrendo de fato no local, que vêm ressignificando seu uso.

Foi realizada pesquisa exploratória no local e a análise de alguns documentos que viabilizou a identificação de questões de ordem burocráticas que, possivelmente, impediram o retorno de alguns dos antigos ocupantes/permissionários ao Mercado, dentre outros fatores sociais que ensejam este trabalho. 


\section{Materiais e Métodos}

Será realizado um estudo qualitativo, cujas técnicas aplicadas serão: a) o questionário escrito, com perguntas abertas e fechadas, aplicado diretamente aos atuais frequentadores do Mercado, sem identificação do participante; b) o questionário escrito, com perguntas abertas e fechadas, aplicado aos antigos frequentadores do Mercado, sem identificação do participante; c) A entrevista aos antigos permissionários do Mercado Público que permaneceram no local após a revitalização, podendo o entrevistado identificar-se ou não; d) A entrevista aos novos permissionários do Mercado, que instalaram seus comércios após a revitalização, podendo o entrevistado identificar-se ou não; e) A entrevista realizada com os antigos permissionários do Mercado Público, que saíram na ocasião do início das obras e não retornaram ao local após a revitalização, podendo o entrevistado identificar-se ou não; f) A revisão bibliográfica - as teorias e os conceitos que darão suporte a presente pesquisa sociológica; e) A técnica da observação; f) A análise de documentos relevantes para a pesquisa; g) A fotografia.

\section{Conclusão}

O presente pesquisa em andamento busca compreender a ressignificação do espaço social do Mercado Público Central da cidade de Pelotas após ter passado pelo processo de requalificação/revitalização, pois dentre os prédios da parte histórica da cidade este foi o que se salientou no que se refere ao uso e meio de sociabilidade.

Assim, de acordo com pesquisa exploratória realizada através de observações não participantes e da fala de alguns dos sujeitos sociais, constata-se que ocorreu de fato mudanças neste espaço público, produzindo relevantes consequências que devem ser identificadas a fim de compreender no que resultou tal ressignificação. Percebeu-se que há idiossincrasia entre antigos e novos ocupantes deste espaço tradicional de Pelotas/RS.

A pesquisa exploratória proporcionou avanços a partir da técnica da observação que foi aplicada no período de novembro de 2015 até o ano corrente de maneira esporádica; por meio da aplicação de 20 questionários on line, para identificar o perfil sociodemográfico do público frequentador antes e depois da revitalização do MPC, sem identificação dos participantes voluntários. E, também por meio de 20 questionários escritos destinados e aplicados aos novos e antigos permissionários do Mercado Central na atualidade- pós revitalização. 


\section{REFERÊNCIAS}

ARANTES, Antonio. Patrimônio cultural e cidade. In: FORTUNA, Carlos e LEITE, Rogério Proença (Orgs.). Plural de Cidade: léxicos e culturas urbanas. Coimbra: Almedina, 2009.

BALSAN, Rosane e UEDA, Vanda. O comércio informal de Pelotas: características e contradições no centro histórico da cidade. Boletim Gaúcho de Geografia, vol. 23, no. 1, mar., p. 71-80, 1998. Disponível em:

http://seer.ufrgs.br/index.php/bgg/article/view/38382/25685. Acesso em 25/05/2016.

BOURDIEU, Pierre. Gosto de classe e Estilo de Vida. In: ORTIZ, Renato (Org.). Pierre Bourdieu. São Paulo: Ática, 1983.

Razões Práticas: sobre a teoria da ação. Campinas: Papirus, 1996.

BRASIL. Programa Monumenta reinaugura o Mercado Público de Pelotas - RS. IPHAN Instituto do Patrimônio Histórico e Artístico, Brasília, 19 dez. 2012. Disponível em: http://portal.iphan.gov.br/noticias/detalhes/741/programa-monumentareinaugura-o-mercadopublico-de-pelotas-\%E2\%80\%93-rs. Acesso em 25/05/2016.

FRÚGOLI JR., Heitor. Centralidade em São Paulo: trajetórias, conflitos e negociações na metrópole. São Paulo: EDUSP, 2000.

Centralidade em São Paulo: trajetórias, conflitos e negociações na metrópole. São Paulo: EDUSP, 2006.

Sociabilidade Urbana. Rio de Janeiro: Jorge Zahar, 2007.

GUTIÉRREZ, Rafael Adrés Barrera. La polisemia y la linguística de gentrificación.

Cadernos Metrópole, vol. 16, no. 32, nov., p. 295-628, 2014.

HARVEY, David. Condição Pós Moderna: Uma Pesquisa sobre as Origens da Mudança Cultural. São Paulo: Loyola, 1992.

LEFÈBVRE, Henri. O direito à cidade. Belo Horizonte: UFMG, 2008.

PARK, Robert Erza. A cidade: Sugestões para investigação do comportamento humano no meio urbano. In: VELHO, Otávio Guilherme (Org.). O Fenômeno Urbano. Rio de Janeiro: Jorge Zahar, 1973.

PEIXOTO, Paulo. Requalificação urbana. In: FORTUNA, Carlos e LEITE, Rogério Proença (Orgs.). Plural de Cidade: léxicos e culturas urbanas. Coimbra: Almedina, 2009.

PELOTAS. Relatório de Cumprimento do Objeto: Convênio nº. 392/2002. Programa Monumenta. Prefeitura Municipal de Pelotas, Pelotas, 2002.

PEREIRA, Alvaro Luis dos Santos. A gentrificação e a hipótese do diferencial de renda: limites explicativos e diálogos possíveis. Cadernos Metrópole, vol. 16, no. 32, nov., p. 295628, 2014. 
REMY, Jean. Gran ciudad y pequeña cuidad: tensiones entre sociabilidad y estética em Simmel, La metodología implícita: forma y autoorganización social. In: MÁRQUEZ, Francisca (Ed.). Ciudades de Gerog Simmel: lecturas contemporáneas. Santiago del Chile: Ediciones Universidad Alberto Hurtado, 2012.

RUBINO, Silvana. Enobrecimento Urbano. In: FORTUNA, Carlos e LEITE, Rogério Proença (Orgs.). Plural de Cidade: léxicos e culturas urbanas. Coimbra: Almedina, 2009.

SERPA, Angelo. O espaço público na cidade contemporânea. 1 ed. 2 reimp. São Paulo: Contexto, 2011.

SIMMEL, Georg. Questões fundamentais da Sociologia: indivíduo e sociedade. Tradução de Pedro Caldas. Rio de Janeiro: Jorge Zahar, 2006.

VARGAS, Heliana Comin e CASTILHO, Ana Luiza Howard de. Intervenções em Centros Urbanos: objetivos, estratégias e resultados. Barueri: Manole, 2006.

VILLELA, Ana Laura Vianna. Proposta de reciclagem - Mercado Público de Pelotas. Faculdade de Arquitetura e Urbanismo, Universidade Federal de Pelotas, Pelotas, 1995.

WIRTH, Louis. O urbanismo como modo de vida (1938). In: VELHO, Otávio Guilherme (Org.). O Fenômeno Urbano. 2 ed. Rio de Janeiro: Jorge Zahar, 1973.

ZUKIN, Sharon. Entre o tecido físico e social das cidades. Entrevista concedida a Heitor Frúgoli Jr. e Julio Cesar Talhari. Tradução de Lilian Gasparetti Abdoullah. Revista Brasileira de Ciências Sociais, vol. 29, no. 84, fev., p. 7-24, 2014. 